\title{
A current generic classification of sap beetles (Coleoptera, Nitidulidae)
}

\author{
A.G. Kirejtshuk
}

Kirejtshuk, A.G. 2008. A current generic classification of sap beetles (Coleoptera, Nitidulidae). Zoosystematica Rossica, 17(1): 107-122.

The list of generic and subgeneric taxa arranged into subfamilies and tribes proposed for sap beetles is given, which includes also new genera [Parapocadius gen. nov. (Nitidulinae: Nitidulini) and Interfaxia gen. nov. (Nitidulinae: Cyllodini)] and subgenera [Semocarpolus subgen. nov. Gaplocarpolus subgen. nov. Askocarpolus subgen. nov. (Carpophilinae: Carpophilus Stephens, 1829)]. The Meoncerus Sharp, 1891; Apsectochilus Reitter, 1874 and Lordyrops Reitter, 1875 are considered as quite distinct each from other above mentioned as from all other generic taxa. In the list there are given the complete synonymy, including new synonymy of generic and subgeneric names [Crepuraea Kirejtshuk, 1990 and Nyujwa Perkovsky, 1990 syn. nov.; Haptoncus Murray, 1864 and Haptoncurina Jelínek, 1977, syn. nov.; Ecnomaeus Erichson, 1843 and Somaphorus Murray, 1864, syn. nov.; Ecnomorphus Motschulsky, 1858; Tribrachys LeConte, 1861 syn. nov.; Stauroglossicus Murray, 1864, syn. nov. and Microxanthus Murray, 1864, syn. nov.; Pria Stephens, 1829 and Allopria Kirejtshuk, 1980, syn. nov.; Megauchenia Macleay, 1825 and Orvoenia Dajoz, 1980, syn. nov.; Tetrisus Murray, 1864 and Pseudoischaena Grouvelle, 1897, syn. nov.; Neopocadius Grouvelle, 1906 and Pseudostelidota Grouvelle, 1906, syn. nov.; Cychramus Kugelann, 1794 and Aethinopsis Grouvelle, 1908, syn. nov.; Mystrops Erichson, 1843, and Cryptoraea Retter, 1873, syn. nov.; Cyllodes Erichson, 1843 and Mecyllodes Sharp, 1891, syn. nov.; Grammorus Murray, 1868 and Colopteroides Watrous, 1982, syn. nov.; Cryptarcha Shuckard, 1839 and Priatelus Broun, 1881 , syn. nov.]. For some taxa the rank is changed, namely, Lordyra Gemminger \& Harold, 1868, stat. nov. is regarded as a subgenus of Lasiodactylus Perty, 1830-1834; Brounthina Kirejtshuk, 1997, stat. nov. as a subgenus Neopocadius Grouvelle, 1906 and Teichostethus Sharp, 1891, stat. nov. as a subgenus of Hebascus Erichson, 1843, while the taxa Coxollodes Kirejtshuk, 1987 (stat. nov.) and Onicotis Murray, 1864 (stat. nov.) are regarded as separate genera. The new taxa and new taxonomical proposals are supplied with corresponding data in the notes below the list. In these notes there are also proposed the new synonymy for the following species names: Carpophilus (Ecnomorphus) acutangulus Reitter, 1884 and C. (E.) cingulatus Reitter, 1884, syn. nov.; C. (E.) bakeweli Murray, 1864; C. (E.) planatus Murray, 1864, syn. nov. and C. (E.) aterrimus Macleay, 1864, syn. nov.; C. (E.) debilis Grouvelle, 1897 and C. (E.) opaculus Grouvelle, 1897, syn. nov.; C. (E.) luridipennis Macleay, 1873 and C. (E.) loriai Grouvelle, 1906, syn. nov.; C. (E.) murrayi Grouvelle, 1892 and C. (E.) hebetatus Grouvelle, 1908, syn. nov.; C. (E.) plagiatipennis (Motschulsky, 1858) and $C$. (E.) nigricans Grouvelle, 1897, syn. nov.; C. (E.) terminalis Murray, 1864 and C. (E.) gentilis Murray, 1864, syn. nov.; Lasiodactylus brunneus Perty, 1830; L. centralis Cline et Carlton, 2004, syn. nov.; L. falini Cline et Carlton, 2004, syn. nov. and L. kelleri Cline et Carlton, 2004, syn. nov.); Pallodes opacus Grouvelle, 1906 and P. loriai Grouvelle, 1906, syn. nov.; Cyllodes fauveli Grouvelle, 1903 and Pallodes vagepunctus Grouvelle, 1903, syn. nov.; Pallodes jucundus Reitter, 1873 and Mecyllodes nigropictus Sharp, 1891, syn. nov.; Pallodes birmanicus Grouvelle, 1892 and P. kalingus Kirejtshuk, 1987, syn. nov.; P. gestroi Grouvelle, 1906 and P. misellus Grouvelle, 1906, syn. nov.; P. ruficollis Reitter, 1873 and P. cyanescens Grouvelle, 1898, syn. nov.; Grammophorus caelatus Gerstäcker, 1864 and Colopterus striaticollis Murray, 1864, syn. nov. In connection with a preliminary revision of many type series of the family and the mentioned taxonomical changes for some species names are established new taxonomical interpretation, namely: Pleoronia nitida (Grouvelle, 1898), comb. nov. (Axyra: Axyrodes); Parapocadius immerizi (Grouvelle, 1899), comb. nov. (Pallodes); Camptodes ruficornis (Grouvelle, 1898), comb. nov. (Pallodes); Neopallodes aestimabilis (Grouvelle, 1906), comb. nov. (Pallodes); N. alluaudi (Grouvelle, 1899), comb. nov. (Pallodes); N. aterrimus (Grouvelle, 1906), comb. nov. (Pallodes); N. dorsalis (Grouvelle, 1896), comb. nov. (Pallodes); N. fairmairei (Grouvelle, 1906), comb. nov. (Pallodes); N. incertus (Grouvelle, 1906), comb. nov. (Pallodes); N. klugi (Grouvelle, 1896), comb. nov. (Pallodes); N. limbicollis (Reitter, 1880), comb. nov. (Pallodes); N. militaris (Grouvelle, 1906), comb. nov. (Pallodes); N. niger (Grouvelle, 1906), comb. nov. (Pallodes); N. nigrocyaneus (Grouvelle, 1906), comb. nov. (Pallodes); N. nitidus (Grouvelle, 1906), comb. nov. (Pallodes); N. orthogonus (Grouvelle, 1906), comb. nov. (Pallodes); N. perrieri (Grouvelle, 1906), comb. nov. (Pallodes); N. scutellaris (Grouvelle, 1906), comb. nov. (Pallodes); N. 
sicardi (Grouvelle, 1906), comb. nov. (Pallodes); N. sikordi (Grouvelle, 1896), comb. nov. (Pallodes); N. variabilis (Grouvelle, 1896), comb. nov. (Pallodes); Coxollodes cyrtusoides (Reitter, 1884), comb. nov. (Pallodes); C. amamiensis (Hisamatsu, 1956), comb. nov. (Pallodes); Coxollodes opacus (Grouvelle, 1906), comb. nov. (Pallodes); C. parvulus (Grouvelle, 1908), comb. nov. (Pallodes); C. reitteri Kirejtshuk, 1987, comb. nov. (Pallodes); Pallodes fauveli (Grouvelle, 1903), comb. nov. (Cyllodes); Cyllodes jucundus (Reitter, 1873), comb. nov. (Pallodes); Interfaxia fasciata (Sharp, 1891), comb. nov.; Onicotis auritus Murray, 1864 comb. nov.; Platyarcha biguttata (Motschulsky, 1858), comb. nov. (Carphophilus: Ecnomorphus); Cryptarcha optanda (Broun, 1881), comb. nov. (Priateles). Besides, because of the new interpretation for Pallodes laetus Grouvelle, 1898, which should be transfered to the genus Camptodes, C. grouvellei nom. nov. (non Camptodes laetus Kirsch, 1873) is proposed. For the generic names Perilopa Erichson, 1843 and Meoncerus Sharp, 1891 the type species are designated as well as for Pallodes laetus Grouvelle, 1898 (Camptodes grouvellei nom. nov.) the lectotype designation is made.

A.G. Kirejtshuk, Zoological Institute of Russian Academy of Sciences, Sainct Petersburg, 199034,Russia.E-mail:agk@zin.ru,ak3929@ak3929.spb.edu, alexander_kirejtshuk@ yahoo.com

The system of the family Nitidulidae has been greatly changed by efforts of many students and essentially improved during the last 20-30 years. However there are no comprehensive publications devoted a general view on the system of this family. It is partly connected with the fact that some important aspects of the system of this group are still needed to be considered. Recently the chapter on Nitidulidae in the Palaearctic "catalogue" appeared (Jelínek \& Audisio, 2007). It contains some principal deficiencies stimulated a preparation of this paper. These deficiencies can be explained that not all necessary taxonomic data achieved were taken into account by the author of the catalogue and a part of published information was dropped from the author's consideration. The author of this paper is aware that such a situation became possible because he having known nearly all groups of this family obtained from the recent and past faunas could publish only a small portion of these data and he has paid not enough attention for preparation of detailed generalizations on the family system. This paper aims partly to compensate the mentioned defects, although a more thorough analysis of the systematic blocks of this family will be discussed in the coming monographs (Kirejtshuk, in preparation). These monographs will cover a detailed review of bibliography, and therefore the writer restricted the references only by the list of most appropriate sources supplementary to the notes here included and the publications with authors and years of taxa available in the Zoological Records and different catalogues (Grouvelle, 1913; Jelínek \& Audisio, 2007; Ponomarenko \& Kirejtshuk, 2008 etc.) are mostly omitted to make this paper as compact as possible.

The core of the paper includes the list of generic names arranged into subfamilies, tribes (when they can be outlined) and the synonyms of each taxon are put together according to dates of their publication (the principle of priority). Besides, if a genus can be divided into recognizable subgenera, the latter were listed as well. To prepare such a complete arrangement of the taxa above the species level the author was obliged to include some new data (new synonymy or other taxonomic propositions) which are explained bellow the list of taxa and these explanations in the necessary cases are provided with appropriate comments (diagnoses, composition and so on). In all cases new synonymy is proposed on base of re-testing the type species of genera and type series of all synonymysed species names. Nevertheless, some new taxa of the tribe and genus rank are still in preparation by the author and his collaborators and not included in the list and notes to it. In some important cases the type species are designated, although in other cases, when they have already designated in previous publications, the mention of them are omitted to shorten the volume of this paper.

The systematic construction of the family here represented should be regarded as a preliminary version of a system based on the phylogeny and history. At the moment, not-convergent (monophyletic) origin of Cillaeinae and Cryptarchinae is accepted only because they have the formal structural characters uniting these subfamilies. It can be expected that a more detailed study of historic development of these groups and more detailed comparison of their structures will demonstrate their polyphyletic state. While the origin of the family in general remains rather obscure, the relationship of Nitidulina ecliva Martynov, 1927 is not clear and this name is omitted in the list below. To clarify the systematic position of this and some other fossil species needs a further careful research of many Cucujoiformian groups from the Jurassic and Cretaceous. The recent subfamilies Calonecrinae and Maynipeplinae 
are certainly closely related to other sap beetles are provisionally regarded in the composition of the Nitidulidae, although these small groups are so distinct that they could be excluded from this family as two taxa with the family rank. Finally, the palaeoendemic genera with unclear familiar attribution described among the Nitidulidae which should be regarded rather far from this family are also omitted in the list [f.i., Sinonitidulina Hong, 1983; Sinosoronia Zhang, 1992 etc.]

\section{Subfamily CALONECRINAE Kirejtshuk, 1982}

\section{Calonecrus Thomson, 1857}

II. Subfamily MAYNIPEPLINAE Kirejtshuk, 1998

Maynipeplus Kirejtshuk, 1998

\section{Carpophilinae-lineage}

III. Subfamily EPURAEINAE Kirejtshuk, 1986

Tribe Epuraeini Kirejtshuk, 1986

Crepuraea Kirejtshuk in Kirejtshuk et Ponomarenko, 1990 (Nyujwa Perkovsky, 1990, syn. nov.) ${ }^{(1)}$

Epanuraea Scudder, 1892

Epuraea Erichson, 1843

Subgenera

Epuraea Erichson, 1843

Ceroncura Kirejtshuk, 1994

Dadopora Thomson, 1859

Strophoraea Kirejtshuk et Kvamme, 2001

Epuraeanella Crotch, 1874 (=Omosiphora Reitter, 1875)

Ommoraea Kirejtshuk, 1998

Micruria Reitter, 1874 (=Micrurula Reitter, 1884)

Aphenolia Reitter, 1884

Africaraea Kirejtshuk, 1989

Apria Grouvelle, 1919

Haptoncus Murray, 1864 (=Haptoncura

Reitter, 1875;

Haptoncurina Jelínek, 1977, syn. nov.) ${ }^{(2)}$

Blackburnaea Kirejtshuk et Kvamme, 2001

Marinexa Kirejtshuk, 1989

Polinexa Kirejtshuk, 1989

Horniraea Kirejtshuk et Pakaluk, 1996

Orthopeplus Horn, 1879

Grouvellia Kirejtshuk, 1984

Mystronoma Kirejtshuk, 1990

Amedanyraea Kirejtshuk et Pakaluk, 1996

Amystrops Grouvelle, 1906 (=Propetes Reitter, 1875, non Walker 1851; Amystrops Grouvelle, 1906; Platychorinus Grouvelle, 1906; Platy- choropsis Grouvelle, 1912; Haptoncognathus Gillogly, 1962)

Subgenera

Amystrops Grouvelle, 1906

Mandipetes Kirejtshuk, 1997

Parepuraea Jelínek, 1977

Ceratomedia Kirejtshuk, 1990

Trimenus Murray, 1864

Ecnomaeus Erichson, 1843 (=Somaphorus

Murray, 1864, syn. nov.) ${ }^{(3)}$

Platychorina Grouvelle, 1905

Baloghmena Kirejtshuk, 1987

Stauromenus Kirejtshuk et Kvamme, 2001

Tribe Taenioncini Kirejtshuk, 1998

Taenioncus Kirejtshuk, 1984

Raspinotus Kirejtshuk, 1990

Taeniolinus Kirejtshuk, 1998

Carpocryraea Kirejtshuk, 1998

Csiromenus Kirejtshuk et Kvamme, 2001

Eutaenioncus Kirejtshuk et Kvamme, 2001

IV. Subfamily CARPOPHILINAE Erichson, 1943

Procarpophilus de Jong, 1953

Carpophilus Stephens, 1829

Subgenera

Carpophilus Stephens, 1829

Megacarpolus Reitter, 1919

Semocarpolus Kirejtshuk, subgen. nov. ${ }^{(4)}$

Gaplocarpolus Kirejtshuk, subgen. nov. ${ }^{(5)}$

Askocarpolus Kirejtshuk, subgen. nov. ${ }^{(6)}$

Plapennipolus Kirejtshuk, 1997

Ecnomorphus Motschulsky, 1858 (=Tri-

brachys LeConte, 1861, syn. nov.; Eidocolas-

tus Murray, 1864, syn. nov.; Stauroglossicus

Murray, 1864, syn. nov. ; Microxanthus Mur-

ray, 1864, syn. nov.; Idocolastus Gemminger et Harold, 1868) (7)

Caplothorax Kirejtshuk, 1997

Myothorax Murray, 1864

Nitops Murray, 1864 (=Endomerus Murray, 1864)

Subgenera

Nitops Murray, 1864

Urocarpolus Kirejtshuk, 1997

Ctilodes Murray, 1864

Loriarulus Kirejtshuk, 1987

Vulpixenus Kirejtshuk, 1990

Urophorus Murray, 1864 (?=Heterodontus Murray, 1864 , nom. nudum)

Subgenera

Urophorus Murray, 1864

Anophorus Kirejtshuk, 1990

V. Subfamily AMPHICROSSINAE Kirejtshuk, 1986

Amphicrossus Erichson, 1843 (=Cametis Motschulsky, 1863; Lobostoma Fairmaire, 1892; 
Rhacostoma Berg, 1898; Nitidopecten Reichensperger, 1913)

\section{Nitidulinae-lineage}

\section{Subfamily MELIGETHINAE Thomson, 1859 (Meligethina)}

Meligethinus Grouvelle, 1906 (=Prianella Reitter, 1919)

Pria Stephens, 1829 (=Laria Scopoli, 1763, Cormyphora Laporte de Castelneau, 1840; pars; Allopria Kirejtshuk, 1980, syn. nov.) ${ }^{(8)}$

Microporodes Endrödy-Younga, 1978

Anthystrix Kirejtshuk, 1984

Micropria Grouvelle, 1899 (=Metapria Grouvelle, 1908/1909))

Cyclogethes Kirejtshuk, 1979

Cryptarchopria Jelínek, 1975

Kabakovia Kirejtshuk, 1979

Horakia Jelínek, 2000

Microporum C. Waterhouse, 1876 (=Probaenus

C. Waterhouse, 1876; Microporellus EndrödyYounga, 1978)

Palmopria Endrödy-Younga, 1978

Cornutopria Endrödy-Younga, 1978

Lechanteuria Endrody-Younga, 1978 (=Prianella Lechanteur, 1955, non Reitter, 1919)

Meligethes Stephens, 1829

Subgenera

Chromogethes Kirejtshuk, 1989

Lariopsis Kirejtshuk, 1989

Clypeogethes Scholtz, 1932 (=Idiogethes Kirejtshuk, 1977)

Meligethes Stephens, 1829 (=Odontogethes Reitter, 1871)

Astylogethes Kirejtshuk, 1992

Acanthogethes Reitter, 1871

VII. Subfamily NITIDULINAE Latreille, 1802

A. Tribe Nitidulini Erichson, 1843 (=Thalycrina Thomson, 1859; Pocadiini Seidlitz, 1872; Orvoenini Dajoz, 1980, syn. nov. $)^{(10)}$

\section{Nitidula-complex}

Nitidula Fabricius 1775

Omosita Erichson, 1843 (=Saprobia Ganglbauer, 1899)

\section{Soronia-complex}

+Microsoronia Kirejtshuk et Kurochkin, 2008 Soronia Erichson, 1843 (=Platipidia Broun, 1893)

Lobiopa Erichson, 1843 (=? Axyrodes Murray, 1867 , nom. nudum $)^{(9)}$
Omosiphila Kirejtshuk, 1990

Temnoracta Kirejtshuk, 1988

Hisparonia Kirejtshuk, 2003

Ornosia Grouvelle, 1899

Pleoronia Kirejtshuk, 2003 (=? Axyrodes Mur-

ray, 1867 , nom. nudum) ${ }^{(9)}$

Amphotis Erichson, 1843

Macleayania Kirejtshuk, 2003

Sebastianiella Kirejtshuk, 1995

Annachramus Kirejtshuk, 1995

Stenoronia Kirejtshuk, 2003

\section{Prometopia-complex}

Prometopia Erichson, 1843

Subgenera

Prometopia Erichson, 1843

Parametopia Reitter, 1884

+ Palaeometopia Kirejtshuk et Poinar, 2007

Cacconia Sharp, 1890

\section{Megauchenia-complex}

Axyra Erichson, 1843 (=Galaor Thomson, 1858) Megauchenia Macleay, 1825 (=Ischaena Erichson, 1843; Orvoenia Dojoz, 1980, syn. nov.) ${ }^{(10)}$

Tetrisus Murray, 1864 (=Pseudoischaena Grouvelle, 1897, syn. nov.) (11)

Megaucheniodes Audisio et Jelínek, 1993

Taraphia Audisio et Jelínek, 1993

Pseudoplatychora Grouvelle, 1890

\section{Ipidia-complex}

Ipidia Erichson, 1843

Subgenera Ipidia Erichson, 1843

Hemipidia Kirejtshuk, 1992

Platychora Erichson, 1843 (=Pherocopis Thomson, 1858) ${ }^{(12)}$

Taracta Murray, 1867

Psilotus Fischer, 1829 (=Cerophorus Laporte de Castelneau, 1840)

Perilopa Erichson, 1843

\section{Phenolia-complex}

Stelidota Erichson, 1843

Phenolia Erichson, 1843 (Lordites auctorum, non Erichson, 1843; Lasiodactylus auctorum, non Perty, 1830-1834)

Subgenera

Aethinodes Blackburn, 1891

Lasiodites Jelínek, 1999

Phenolia Erichson, 1843

Plesiothina Kirejtshuk, 1990

Gaulodes Erichson, 1843

Ussuriphia Kirejtshuk, 1992

Ostomarcha Kirejtshuk, 2006 


\section{Perilopsis-complex}

Epuraeopsis Reitter, 1875

Perilopsis Reitter, 1875

Subgenera

Perilopsis Reitter, 1875

Testudoraea Kirejtshuk, 1986

Cratonura Reitter, 1875

\section{Aethina-complex}

Psilonitidula Heller, 1916

Lasiodactylus Perty, 1830-1834 (=Nitidulingen Gillogly, 1965) ${ }^{(13)}$

Subgenera

Lasiodactylus Perty, 1830-1834

Lordyra Gemminger \& Harold, 1868, stat. nov. ${ }^{(13)}$

Neopocadius Grouvelle, $1906^{(13)}$

Subgenera

Neopocadius Grouvelle, 1906 (=Pseudostelidota Grouvelle, 1906, syn. nov.) ${ }^{(13)}$

Brounthina Kirejtshuk, 1997, stat. nov. ${ }^{(13)}$

Australaethina Kirejtshuk et Lawrence, 1999 (=Idaethina Reitter, 1875, non Gemminger et Harold, 1868. et non Olliff, 1884)

Aethina Erichson, 1843 (=Aethinopa Reitter, 1875; Pseudomystrops Grouvelle, 1912/1913; Meligethopsis Rebmann, 1944)

Subgenera

Aethina Erichson, 1843

Cleidorura Kirejtshuk et Lawrence, 1999

Idaethina Gemminger et Harold, 1868, (=Macroura Reitter, 1873, non Meuschen, 1778, non Loew, 1845; Idaethina Olliff, 1884, non Reitter, 1875; Olliffura Jelínek et Kirejtshuk, 1986)

Circopes Reitter, 1873

Ithyra Reitter, 1873

Anister Grouvelle, 1901 (=Oturovana Reitter, 1915)

\section{Pocadius-complex ${ }^{(14)}$}

+Omositoidea Schaufuss, 1891

Atarphia Reitter, 1884

Hebasculinus Kirejtshuk, 1992

Hebascus Erichson, 1843

Subgenera

Hebascus Erichson, 1843

Teichostethus Sharp, 1891, stat. nov. (Trichostethus) $^{(15)}$

Hyleopocadius Jelinek, 1977

Kryzhanovskiella Kirejtshuk, 2006

Niliodes Murray, 1868

Physoronia Reitter, 1884 (=Lordyrodes Reitter, 1884; Pocadioides Ganglbauer, 1899; Osotima Rebmann, 1944)
Pocadites Reitter, 1884

Pocadius Erichson, 1843

Tagmolycra Kirejtshuk et Leschen, 1998

Parapocadius gen. nov. ${ }^{(16)}$

Pleuroneces Olliff, 1891

Thalycra Erichson, 1843 (=Perthalycra Horn, 1879)

Pseudothalycra Howden, 1962

Quadrifrons Blatchley, 1916

Neothalycra Grouvelle, 1899

Thalycrinella Kirejtshuk in Kirejtshuk et Leschen, 1998

Pocadionta Lucas, 1920 (=Pocadiopsis Grouvelle, 1898, non Fairmaire, 1896)

Thalycrodes Blackburn, 1891

Rixerodes Kirejtshuk et Lawrence, 1992

Australycra Kirejtshuk et Lawrence, 1992

Pocadiolycra Kirejtshuk et Leschen, 1998

B. Tribe Cychramini Lacordaire, 1854 (1855) (Cychramides)

+Cychramites Wickham, 1913

Cychramus Kugelann, 1794 (=Campta Stephens, 1830; Aethinopsis Grouvelle, 1908, syn. nov. $)^{(17)}$

Xenostrongylus Wollston, 1854 (=Strongyllodes

Kirejtshuk, 1992)

Subgenera

Xenostrongylus Wollaston, 1854

Strongylolasius Reitter, 1911

Oxystrongylus Reitter, 1911

Kirejtshukostrongylus Audisio et Jelínek in

Audisio, Mariotti, Jelínek \& DeBiase 2001

Axychramus Kirejtshuk, 1996

Ceratochramus Kirejtshuk, 1986

C. Tribe Mystropini Murray, 1864 (Mystropidae)

Mystrops Erichson, 1943 (=Priops Reitter, 1873; Cryptoraea Retter, 1873, syn. nov.; Eumystrops Sharp, 1889) ${ }^{(18)}$

Anthepurops Kirejtshuk, 1996

Anthocorcina Kirejtshuk, 1996

Platychorodes Reitter, 1884

Cychrocephalus Reitter, 1873 (=Cychropiestus Reitter, 1875)

Nitidulora Reitter, 1873

Palmostrops Kirejtshuk et Jelínek, 2000

D. Tribe Cyllodini Everts, 1898 (=Strongylini Sturm, 1844 (Strongylinae), non Müller, 1780; Arborotubini Leschen et Carlton, 2004)

+ Cyllolithus Kirejtshuk in Kirejtshuk et Ponomarenko, 1990

Somatoxus Sharp, 1891 (=Somatorus Grouvelle, 1891, err.)

Cyclocaccus Sharp, 1891 


\section{Cyllodes-complex}

Camptodes Erichson, 1843 (=Eucamptodes Sharp, 1890)

Meoncerus Sharp, $1891^{(19)}$

Apsectochilus Reitter, 1874, distinct genus ${ }^{(19)}$ Lordyrops Reitter, 1875, distinct genus ${ }^{(19)}$

Carinocyllodes Leschen, 1999

Cyllodes Erichson, 1843 (=Strongylus Herbst, 1792, non Muller, 1780; Volvoxis Kugelann, 1794; Mecyllodes Sharp, 1891, syn. nov.; Pseudocamptodes Grouvelle, 1896) (20)

Eusphaerius Sharp, 1891

Viettherchnus Kirejtshuk, 1985

Ceramphosia Kirejtshuk et Kirk-Spriggs, 1996

Camptomorphus Grouvelle, 1908

Pallodes Erichson, $1843^{\text {(21) }}$

Coxollodes Kirejtshuk, 1987, stat. nov. ${ }^{(21)}$

Neopallodes Reitter, 1884

Cyllodesus Reitter, 1877 (=Strongylomorphus

Reitter, 1875, non Motschulsky, 1853)

\section{Oxycnemus-complex}

Oxycnemus Erichson, $1843^{(22)}$

Eugoniopus Reitter, 1884 (22)

Psilopyga LeConte, 1853 (22)

Interfaxia gen. nov. ${ }^{(22)}$

Triacanus Erichson, 1843 (=Tricanus auctorum)

Monafricus Kirejtshuk, 1995

Gymnocychramus Lea, 1922

Pycnocnemus Sharp, 1891

\section{Arborotubus-complex}

Arborotubus Leschen et Carlton, 2004

E. Tribe Cychramptodini Kirejtshuk et Lawrence, 1992

Cychramptodes Reitter, 1874

Miskoramus Kirejtshuk et Lawrence, 1992

Cylindroramus Kirejtshuk et Lawrence, 1992

F. Tribe Lawrencerosini Kirejtshuk, 1990

Lawrencerosus Kirejtshuk, 1990

Krakingus Kirejtshuk, 1990

Koryaga Kirejtshuk, 1990

Koryaginus Kirejtshuk, 1990

VIII. Subfamily CILLAEINAE Kirejtshuk et Audisio, 1986

Gonioryctus Sharp, 1878 (=Goniothorax Sharp, 1908; Nesapterus Sharp, 1908; Eunitidula Sharp, 1908)

Orthostolus Sharp, 1908

Apetasimus Sharp, 1908 (=Cyrtostolus Sharp, 1908)
Eupetinus Sharp, 1908 (=Apetinus Scott, 1908)

Prosopeus Murray, 1864 (=Prosopius Gemminger et Harold, 1868; Nesopeplus Sharp, 1908; Nesopetinus Sharp, 1908)

Cillaeopeplus Sharp, 1908 (=Notopeplus Sharp, 1908)

Colopterus Erichson, 1842 (=Colastus Erichson, 1843)

Colopterus Erichson, 1843

Cyllopodes Murray, 1864

Grammorus Murray, 1868 (=Grammophorus

Gerstäcker, 1864, nec Solier, 1851; Colopteroides

Watrous, 1982, syn. nov.) (23)

Grouvellepeplus Kirejtshuk, 2001

Brachypeplus Erichson, 1842 (=Nitidulopsis

Walker, 1858; Tasmus Murray, 1864)

Subgenera

Brachypeplus Erichson, 1842

Selis Murray, 1864

Leiopeplus Murray, 1864

Idosoronia Schaufuss, 1891

Teloconus Grouvelle, 1916

Tokocillaeus Kirejtshuk, 2001

Onicotis Murray, 1864, stat. nov. ${ }^{(24)}$

Campsopyga Murray, 1864 (=Hypodetus Murray, 1964).

Cillaeus Laporte de Castelneau, 1835

Subgenera

Cillaeus Laporte de Castelneau, 1835

Xanthopeplus Fairmaire, 1880

Paracillaeopsis Kirejtshuk, 2001

Cillaeopsis Grouvelle, 1899

Halepopeplus Murray, 1864 (=Chalepopeplus

Gemminger et Harold, 1868)

Liparopeplus Murray, 1864 (=Carpophilops

Grouvelle, 1898)

Halepopeplus Murray, 1864

Adocinus Murray, 1864

Platynema Ritsema, 1885 (=Orthogramma

Murray, 1864, not Guenée 1852 et nec R. L.

(Reichenbach, Leipzig), 1817)

Ithyphenes Murray, 1864

Macrostola Murray, 1864

Macrostolops Grouvelle, 1916

Conotelus Erichson, 1843

X. Subfamily CRYPTARCHINAE Thomson, 1859 (=Ipinae Erichson, 1843; Ipsomorpha Reitter, 1873)

A. Tribe Cryptarchini (=Pityophagini Fauconnet, 1896; Glischrochilini Iablokoff-Khnzoryan, 1966)

Cnips Philippi, 1864

Cnipsarcha Jelínek, 1982

Cryptarcha Shuckard, 1839 (=Cryptarchus

Heer, 1843; Priatelus Broun, 1882 (pro Priateles

Broun, 1881), syn. nov.; Lepiarcha Sharp, 1891;

Liarcha Sharp, 1891; Cryptarchula Ganglbauer, 
1899; Africanips Lechanteur, 1959; Cryptarchina Iablokoff-Khnzoryan, 1966) ${ }^{(25)}$

Homepura Broun, 1893 (=Inopria Broun, 1921)

Kaszabena Kirejtshuk, 1987

Paromia Westwood, 1850 (=Lioschema Fairmaire, 1861; Aparomia Redtenbbacher, 1867)

Paromidia Reitter, 1873

Pityophagus Shuckard, 1839

Glischrochilus Reitter, 1873 (Ips Fabricius,

1777, non DeGeer, 1775)

Subgenera

Glischrochilus Reitter, 1873

Librodor Reitter, 1884 (=Cryptarchips

Reitter, 1911; Cephalips Arrow, 1931)

Gymnoparomius Kirejtshuk, 1987

B. Tribe Platyarchini Kirejtshuk, 1998

Platyarcha Kirejtshuk, 1987

Amlearcha Kirejtshuk, 1987

C. Tribe Arhinini Kirejtshuk, 1987

Ceratarhina Kirejtshuk, 1981

Arhina Murray, 1867

Arhinella Kirejtshuk, 1981

D. Tribe Eucalosphaerini Kirejtshuk, 1987

Eucalosphaera Jelínek, 1978 (=Calosphaera Jelínek, 1974, non Campbell, 1951)

X. Subfamily CYBOCEPHALINAE Jaquelin du Val, 1858 (Cybocephalites)

Cybocephalus Erichson, 1844 (=Phantazomerus J. Duval, 1854; Stagnomorpha Wollaston, 1854; Acribis C.Waterhause, 1877; Dissia Chobaut, 1896)

Subgenera

Cybocephalus Erichson, 1843

Theticephalus Kirejtshuk, 1988

Pycnocephalus Sharp, 1891

Hierronius Endrödy-Younga, 1968

Pastillodes Endrödy-Younga, 1968

Taxicephomerus Kirejtshuk, 1994

Horadion Endrödy-Younga, 1976

Pastillus Endrödy-Younga, 1962

Endrodiellus Endrödy-Younga, 1962

\section{INCERTAE SEDIS}

+Miophenolia Wickham, 1916

Nodola Brethes 1925 (?=Cybocephalus)

+Oligamphotis Theobald, 1937

Prioschema Reitter, 1976

\section{Notes:}

1. The name Crepuraea was published the in $2 \mathrm{~d}$ issue of Palaeontological Journal in 1990 (type species: Crepuraea archaica Kirejtshuk in Kirejtshuk et Ponomarenko, 1990, by original designation), while Nyujwa syn. nov. (type species: Nyujwa zherichini Perkowsky, 1990, by monotypy) appeared in the 4th one of the same year. The latter completely corresponds the representatives of the former originated from the same site (Baissa), they should be regarded as synonyms. Another problem is that among the congeners described in composition of Crepuraea one species named as $C$. zherichini and in this case $N$. zherichini should be also recognized as a junior homonym of $C$. zherichini. At the present, the relation of the holotype of $N$. zherichini with other members of the genus is still unclear and a further comparison of the specimens collected in Baissa is needed.

2. The synonymy of names Haptoncus (type species: Haptoncus tetragonus Murray, 1864, designated by Parsons, 1843) and Haptoncurina syn. nov. (type species: Epuraea angustula Motschulsky, 1863, non Epuraea angustula Sturm, 1844, by original designation) should be regarded as evident, because some Indo-Malayan species of Haptoncus [E. (H.) concolor Murray, 1864 and $E$. (H.) fallax (Grouvelle, 1897)] and the members of Haptoncurina show a variability in the subgeneric disagnostic characters making the discrimination of the subgenera quite problematic.

3 . The synonymy of names Ecnomaeus (type species: Ecnomaeus planus Erichson, 1843, by monotypy) and Somaphorus syn. nov. (type species: Somaphorus ferrugineus Murray, 1864, by monotypy) should be recognized, as both type species belong to the same group of clear relatives distriduted in the subequatorial areas of the East Hemisphere.

This group was erroneously put into the subfamily Cilaeinae (Kirejtshuk, 1986), because the elytra of its species remain two last abdominal segments uncovered and somewhat more compact antennal club than in other groups of Epuraeinae. Although the structure of the male abdomen in Ecnomaeus species, including shape of the anal sclerite, ventral plate and genitalia, is certainly similar to that in other groups of the subfamily Epuraeinae, but not to that in Cillaeinae. Besides, the structure of thorax of Ecnomaeus species, particularly prosternal process and mesoventrite is certainly comparable with that in Epuraeinae rather than other sap beetles.

4. The subgenus Semocarpolus subgen. nov. (type species: Carpophilus marginellus Motschulsky, 1858)

Etymology. The name of the subgenus is formed from the Greek "sema" (character) and "carpolus" (Megacarpolus and other generic names with the end "polus") formed in turn from the Greek "carpus" (fruit, foetus). 
Diagnosis: This new subgenus is well characterized by a raised median carina of the mesoventrite, almost rectilinear submesocoxal line and undivided fork-sclerite of tegmen. It seems to be close to Carpophilus sensu str. differing from it only in the mentioned characters and very shallow and indistinct punctures on mesoventrite. Species of this new subgenus have some resemblance to those of Megacarpolus, but their bodies are reddish brown in coloration, smaller and more convex, with very steeply sloping pronotal and elytral unexplanate sides, less compact antennal club, hypopygidium of their males without any additional depression [although the Indo-Malayan species of Megacarpolus are also without clear depression on this sclerite in males]. Species of Semocarpolus subgen. nov. are also similar to the representatives of Gaplocarpolus subgen. nov., but, except for the mentioned distinguishing characters, also have rather distinct dorsal puncturation and only shallow punctures on mesoventrite as well as their females with simple pygidium. Also, the species of this new subgenus are clearly distinguished from Askocarpolus subgen. nov. by more robust and more convex body with very steeply sloping pronotal and elytral unexplanate sides, not projecting posterior pronotal angles, lack of raised depressions on pronotal and elytral disks, and also by lack of paramedian pockets on mesoventrite.

This new subgenus is also characterized by a somewhat loose antennal club between antennomeres 9 and 10, but less loose than that observed among members of Ecnomorphus or even in Askocarpolus subgen. nov. Nevertheless, the antennal club of species of this subgenus is less compact in comparison with that in the representatives of all subgenera which are here regarded as similar and probably related to it [i.e. Megacarpolus, Gaplocarpolus subgen. nov., Askocarpolus subgen. nov. and Carpophilus].

According to N. Hayashi (1978) the larvae of $C$. (S.) marginellus, in contrast to other groups of the subfamily, could be characterized by the indistinct or even absent ocelli and pair of transverse oval patches of sclerotized microscopic asperities on abdominal terga II-VIII.

Bionomy. The species of this new subgenus are associated with different decaying products of plant origin and $C$. (S.) marginellus is a characteristic pest of stored products with an almost world-wide range.

Composition and distribution. This new subgenus is represented only with 4 species: type species with subcosmopolitan range in human stores and under natural conditions mostly in the areas with tropical and subtropical climate; $C$. (S.) rubescens Murray, 1864 distributed in the IndoMalayan region; C. (S.) succisus Erichson, 1943 from Neotropical Region (Central America and
Brazil) and one species under description from the Indo-Malayan Region.

5. The subgenus Gaplocarpolus subgen. nov. (type-species: Carpophilus (Carpophilus) cuneiformis Murray, 1864).

Etymology. The name for this taxon is created from the Greek "gaplos" (meaning simple, solitary, lonely) and "carpolus" used for some names of the Carpophilinae and formed from the Greek "carpus" (fruit, foetus).

Diagnosis. This new subgenus is more similar to the subgenera Askocarpolus subgen. nov., Carpophilus sensu str., Megacarpolus and Semocarpolus subgen. nov. than other groups of the subfamily. It is very distinct from the mentioned taxa by the comparatively sparse puncturation of integument, slightly loose antennal club between antennomeres 9 and 10, spiracles of tergite VI widely transverse, medially convex and moderately widened apex of prosternal process. This new subgenus is also characterized by the following characters: medium body size, subvertical pronotal and elytral sides, slightly curved along procoxae to subflattened prosternal process with strongly widened apex and simple mesoventrite. The members of Gaplocarpolus subgen. nov. have the similar outline of submesocoxal line. Externally species of this new subgenus are more similar to representatives of Semocarpolus subgen. nov. [especially to $C$. (Semocarpolus) rubescens], differing from them not only in the features listed above, but also in widely truncate labral lobes, transverse depression on male metaventrite before anterior edge, submesocoxal line gently curving and slightly deviating from posterior edge of cavities. Besides it, this new subgenus differs also from subgenera:

- Carpophilus sensu str. also in the simple mesoventrite bearing rather shallow indistinct punctures;

- Megacarpolus also in the lighter, smaller and more convex body, more distinct and very sparse puncturation of dorsum, distinct submesocoxal line deviating from the posterior edge of cavities;

- Askocarpolus subgen. nov. also in the even pronotal disk, simple mesoventrite (without trace of paramedian pockets), distinct submesocoxal line deviating from the posterior edge of cavities.

This new taxon is proposed in order to counterbalance the considered groups with comparable hiati in characters. The combination of its peculiarities is corresponding to those of other subgenera of Carpophilus sensu lato.

Bionomy. Imagines of both species of this new subgenus were captured probably in montane forest at elevation of 200-2 $300 \mathrm{~m}$.

Composition and distribution. Three members of this new subgenus (type species and two species 
under description) are known from the Indochinese and Malayan provinces.

6. The subgenus Askocarpolus subgen. nov. (type-species: Carpophilus oblongopunctatus Grouvelle, 1903)

Etymology. The name of the subgenus is composed from the Greek "askos" (chamber, cell, sac) and "carpolus" (Megacarpolus and other generic names with the end "polus") transformed from the Greek "carpus" (fruit, foetus).

Diagnosis. This new subgenus is very distinct from all groups of the subfamily (and the family as a whole) due to a pair of deep paramedian pockets in the middle of mesoventrite situated at level of apex of prosternal process. It is also well characterized by more or less distinct oval paramedian depressions at base of the pronotum and very weak longitudinal depressions in anterior half of elytra, almost simple scarcely lobed meso- and metatarsi, posterior edge of metaventrite with a deep excision between metacoxae, not completely divided fork-sclerite of tegmen and articulated connection between ventral plate and spiculum gastrale of the male.

Appearence of its representatives is also rather similar to that of species in the subgenus Gaplocarpolus subgen. nov., but differs from that in the more or less expressed paramedian depressions at base of pronotum and longitudinal depressions on elytra as well as in distinct anterior angles of pronotum, less strongly sloping pronotal and elytral sides and in shape of the last labial palpomeres strongly widened to apex. This new subgenus shares a certain similarity (particularly in the body shape, characters of puncturation and sculpture of sclerites) to the subgenera Megacarpolus and Semocarpolus subgen. nov., although in addition to characteristic paramedian pockets on mesoventrite, depressions on pronotum and elytra, the representatives of Askocarpolus subgen. nov. differ from those of the first in their somewhat longer elytra, usually more asymmetrical last labial palpomere, lack of sexual dimorphism in structure of 3-segmented antennal club; and from the second - in the less robust and less convex body with more gently sloping pronotal and elytral sides to moderately explanate edges, strongly widened last labial palpomere and projecting posterior pronotal angles.

Besides the characteristic paramedian pockets on mesoventrite as well as depressions on pronotum and elytra, Askocarpolus subgen. nov. differs from other subgenera of the genus Carpophilus sensu lato:

- from Carpophilus sensu str. in the absence of isolated distal plate of mesoventrite divided by median ridge; less steeply sloping pronotal and elytral sides, wider last labial palpomeres, less widely separated of meso- and metacoxae, narrower protarsus, more elongate last abdominal segment in females;

- from Ecnomorphus in the less flattened body and different characters of puncturation and sculpture of integument;

- from Myothorax in the less convex and usually elongate oval body, distinct anterior and posterior angles of pronotum.

Finally, the mentioned paramedian pockets on mesoventrite of the new subgenus under consideration have some analogy with depressions on mesoventrite in Sebastianiella spp. (Nitidulinae) from South Africa.

Bionomy. The species of this new subgenus seem to be associated with decaying fruits and other decaying products of plant origin.

Composition and distribution. This new subgenus is represented only with 5 species ( 4 of them under description) known from the south of the Palaearchearctic Province of Palaearctic Region and Indochinese Province of Indo-Malayan Region, but the type species of the subgenus is described from Darjeeling.

7. The synonymy of the names Ecnomorphus (type-species: Nitidula sexpustulata Fabricius, 1791; designated by Jelínek \& Audisio, 2003); Tribrachys syn. nov. (type-species: Tribrachys caudalis LeConte, 1859; designated by C.T. Parsons, 1943); Eidocolastus syn. nov. (type-species: Colastus plagiatipennis Motschulsky, 1858; designated by Jelínek \& Audisio, 2003); Stauroglossicus syn. nov. (type-species: Stauroglossicus terminalis Murray, 1864: 398; designated by Jelínek \& Audisio, 2003); Microxanthus syn. nov. (type species: Carpophilus tempestivus Erichson, 1843; designated by Jelínek \& Audisio, 2003); Idocolastus (proposed for Eidocolastus) is based on wide comparison of many members of the genus.

The name Tribrachys was treated as a junior synonym of the name Carpophilus in general (Grouvelle, 1913), however, in accordance with the designations of type species the first of mentioned names should be regarded as a junior synonym of Ecnomorphus. The type-species of Tribrachys seems to be closely related to $C$. $(E$.) ligneus Murray, 1864, while the type-species of the Ecnomorphus is very distinct from other groups of the subgenus in some characters, which scarcely could make possible to regard it as a member of separate subgenus. The type-species of Stauroglossicus and Eidocolastus belong to the groups closely related each to another as well as quite similar to the rest groups of the subgenus and, therefore, the last two names should be regarded in composition of the same subgenus together with Tribrachys and Ecnomorphus.

V. Motschulsky (1858) proposed the name Ecnomorphus in connection with the description of E. fulvipes which he compared with the European 
Nitidula sexpustulata Fabricius, 1792. A. Murray (1864) removed E. fulvipes from the subgenus Ecnomorphus, because he decided that the characters listed by V. Motschulsky for this subgenus fitted rather to the European than Indo-Malayan representatives. However, neither A. Murray nor V. Motschulsky designated the type-species of the taxon properly. V. Motschulsky included in Ecnomorphus also E. biguttatus, described by him in the same publication. A. Murray interpreted this name for species of the subgenus Myothorax, supposing that V. Motschulsky under this name described a variety of $C$. (M.) vittiger Murray, 1864. The recent examination of the type series of E. biguttatus showed that the species with this type series indeed should be regarded as a member of the genus Platyarcha Kirejtshuk, 1987 [Platyarcha biguttata (Motschulsky, 1858), comb. nov.: Cryptarchinae, Platyarchini].

The groups which could be regarded as $E c$ nomorphus and Microxanthus do not show any clear hiatus. The alone character which can be used to discriminate them could be the distinctness of posterior angles of the pronotum. However this character sometimes is rather variable even within one species or within one series of the same species and, therefore, it can not be used for a reliable diagnosis. This is a reason to synonymize the taxa Ecnomorphus and Microxanthus.

Composition of the subgenus (in all cases new synonymy is based on re-testing type series): C. (E.) acutangulus Reitter, 1884 (=cingulatus Reitter, 1884, syn. nov.; ? cingulatoides Nakane, 1959 - the latter was proposed taken into consideration the studied variability of the species); C. (E.) alticola Sharp, 1889; C. (E.) antiquus Melsheimer, 1844; C. (E.) apicipennis Fairmaire, 1869; C. (E.) bakeweli Murray, 1864 (=planatus Murray, 1864, syn. nov.; aterrimus Macleay, 1864, syn. nov.); $C$. (E.) brachypterus (Say, 1825); C. (E.) comatus Sharp, 1889; C. (E.) compressus Murray, 1864; C. (E.) confertus Sharp, 1889; C. (E.) corticinus Erichson, 1843; C. (E.) debilis Grouvelle, 1897 (=opaculus Grouvelle, 1897, syn. nov.); C. (E.) deplanatus Boheman, 1854; C. (E.) discoideus LeConte, 1858; $C$. (E.) dubitabilis Grouvelle, 1897; C. (E.) dufaui Grouvelle, 1908; C. (E.) elaterinus Sharp, 1889; C. (E.) epuraeoides Sharp, 1889; C. (E.) extensus Grouvelle, 1908 (=trapezicollis Kirejtshuk, 1995); C. (E.) ferrugineus Murray, 1864; C. (E.) frivolus Murray, 1864; C. (E.) fulvipes Motschulsky, 1858 (=fusculus Motschulsky, 1858); C. (E.) humilis Erichson, 1843; C. (E.) inconspicuous Murray, 1864; C. (E.) lepidus Murray, 1864; C. (E.) ligneus Murray, 1864 (=decipiens Horn, 1879); C. (E.) luridipennis Macleay, 1873 (=loriai Grouvelle, 1906, syn. nov.); C. (E.) marginatus Erichson, 1843; C. (E.) mcnamarai Dobson, 1993; C. (E.) murrayi Grouvelle, 1892 (=hebetatus Grouvelle, 1908, syn. nov. proposed for fulvipes Grouvelle, 1894, non Motschulsky, 1858); C. (E.) plagiatipennis (Motschulsky, 1858) (=bosschai Grouvelle, 1892; dilutus Motschulsky, 1858, non Murray, 1864; nigricans Grouvelle, 1897, syn. nov.); C. (E.) proximus Grouvelle, 1906; C. (E.) senex Murray, 1864; C. (E.) sexpustulatus (Fabricius, 1791) (=abbreviatus Panzer, 1793; bimaculatus Marsham, 1802); C. (E.) sibiricus Reitter, 1879; $C$. (E.) sinuatus Grouvelle, 1917; C. (E.) subplanus Grouvelle, 1917; C. (E.) tempestivus Erichson, 1843; C. (E.) terminalis Murray, 1864 (=gentilis Murray, 1864, syn. nov.); C. (E.) ustulatus Murray, 1864; C. (E.) variabilis Grouvelle, 1897; C. (E.) waterhousei Dobson, 1993; C. (E.) zuni Casey, 1884; and also some dozens of species which will be described in a future monograph of the author devoted to the fauna of the IndoMalayan Region.

8. Because of variability in extent of the development of tarsal claws among some groups of related species the names Pria and Allopria syn. nov. would be reasonable to consider as synonyms.

9. The name Axyrodes was proposed for one undescribed Neotropical species (nomen nudum) and compared with the described African and Himalayan species of Axyra. Later A. Grouvelle put one species to this taxon [Axyra (Axyrodes) nitida Grouvelle, 1898], which indeed is a member of Pleoronia (comb. nov.). At the same time, the characters mentioned by Murray (1867: 170) make possible to assume that having proposed the "Axyrodes" was considered by him as one elongate member of Pleoronia or Lobiopa.

10. The synonymy of the names Megauchenia and Orvoenia syn. nov. (described among Colydiidae) is evident because the type species of the latter, Orvoenia borneensis Dajoz, 1980, is certainly very similar to Megauchenia gracilis Kirejtshuk, 1990. T.K. Pal \& J.F. Lawrence (1986) wrote on similarity of the species of these taxa when they excluded the tribe Orvoenini from the family Colydiidae.

11. The synonymy of the names Tetrisus and Pseudoischaena syn. nov. is quite clear, because the type species of both (Tetrisus cholevoides Murray, 1864, by monotypy and Pseudoischaena longula Grouvelle, 1897, by nomotypy) are closely related and belong to the same species group. The taxa Trimenus and Tetrisus were regarded as subgenera of the same genus in the composition of the subfamily Epuraeainae (Kirejtshuk, 1998), as the type species of them have females looking like rather similar because of probable convergences of external structures. Nevertheless, the males of both are rather different and show a clear attribution of different subfamilies (Epuraeinae and 
Nitidulinae - particularly after the structure of anal sclerite and aedeagus).

12. The genus Perilopa was proposed with 2 species (P. peltidea Erichson, 1843 from Columbia and $P$. vestita Erichson, 1843 from South Africa). Later some species close to the first species from the Neotropical Region were described in composition of this genus, and for the the second species was proposed a separate genus Annachramus (see above). Thus, as the type species of Perilopa should be recognised $P$. peltidea Erichson, 1843 (here designated).

13. The genus Lasiodactylus was confusedly interpreted in many publications (see comments in Kirejtshuk, 1996; Kirejtshuk \& Lawrence, 1999; Jelínek, 1999). This taxon (sensu stricto) includes only one widely spread species [L. brunneus Perty, 1830 (=procerus Erichson, 1843; meridionalis Gillogly, 1965; centralis Cline et Carlton, 2004, syn. nov.; falini Cline et Carlton, 2004, syn. nov.; kelleri Cline et Carlton, 2004, syn. nov.)] rather variable in many characters, including the puncturation, dorsal pubescence, prosternal process, submetacoxal lines, as well as the characters of secondary sexual dimorphism and genitalia (these characters are sometimes used to separate "species": Cline \& Carlton, 2004). Besides, the taxon Lordyra stat. nov. is here regarded as a subgenus of the same genus because its differences from Lasiodactylus consist mainly in the smaller body size, outline and deepness of antennal grooves, flattened apex of prosternal process, confused puncturation and sculpture of its integument, aedeagus comparably shorter and with apex of tegmen isolated by preapical contraction. Lordyra can have 2-3 members [there are three described species names (see Kirejtshuk \& Lawrence, 1999): L. vilosa (Blanchard in Brullé, 1842); L. loretoensis (Bruch, 1938); L. americana (Reitter, 1873) which need to be revised]. The name Lordyra was synonymyzed with Neopocadius by Kirejtshuk \& Lawrence (1999), although in the current interpretation after additional study of the type species and other materials the first is considered as a subgenus of Lasiodactylus, while the second should be regarded separately. The Neopocadius (type species: Neopocadius nitiduloides Grouvelle, 1906, by monotypy) with a junior synonym Pseudostelidota syn. nov. (type species Pseudostelidota setosa Grouvelle, 1906, by monotypy) is known by two mentioned species and should be regarded as a genus closely related to Lasiodactylus and differing from both in the smaller body, submetacoxal lines following closely posterior edge of metacoxal cavity, head without trace of parocullar lines, narrowly lobed tarsi and excised apex of tegmen, and also from Lordyra in the nearly unexpressed antennal grooves, prosternal process roof-shaped at apex.
On the other hand, the Neopocadius is very similar to Brounthina differing from the latter only in the squamose dorsal pubescence, unraised antennal grooves, wider tarsi and longer tegmen without apical excision. It is a reason to regard this $\mathrm{Ne}-$ vazealandian taxon (Brounthina stat. nov.) as a subgenus of Neopocadius.

14. The Pocadius-complex and Thalycracomplex of genera were preliminarily proposed (Kirejtshuk \& Lawrence, 1992; Kirejtshuk, 1996 etc.) for restricted set of genera studied at that time. A. Cline (2005) used these preliminarily proposals for "phylogenetic analysis" of the tribe "Pocadiini", which was treated by him without any diagnosis making possible to discriminate it among other groups of the tribe Nitidulini. At this level of knowledge on diversity of the groups formerly included in the mentioned complexes demonstrates lack of any hiatus between them and, therefore, it seems to be reasonable to consider the only complex of related genera united groups of both complexes recognized before.

15. The related groups included in the taxa $\mathrm{He}$ bascus Erichson, 1843 and Trichostethus Sharp, 1891, stat. nov. show some differences mentioned by J. Jelínek (1975), however, they are not so expressive and, therefore, in order to make ranks of different taxa comparable these taxa are regarded as subgenera of the same generic taxon.

16. The genus Parapocadius gen. nov. (type species: Pallodes emmerezi Grouvelle, 1899)

[the writer studied the lectotype of the type species, $\sigma$ here designated (in collection of Museum National d'Histoire Naturelle, Paris designated by S. Endrödy-Younga) - "I. Maurice (I. Emmerezi)", "coll. Alluaud", "Lectotypus 1899-1966, Pallodes emmerezi Grouvelle, Dr. Endrödy-Younga" and 7 paralectotypes ( $\sigma^{\prime \prime} \sigma^{\prime \prime}$, ㅇ in the same collection and with the same labels (except the designation one)].

Etymology. The name of this new genus is formed from the Greek "para" (near, next to, close by, nearly, along) and generic name Pocadius.

Diagnosis. This genus is rather close to Pocadius and seems to be aberrant insular deviation of it. Nevertheless, the type species of the new genus differs from the members of Pocadius in the antennae longer than head width; subparamental grooves not expressed; mentum very small, somewhat elevated and with emarginate anterior edge; antennal grooves very fine and long, strongly convergent in anterior half and rather divergent posteriorly; slightly convex anterior part of prosternum; distinct intermesocoxal line behind the mesocoxae; shallowly emarginate posterior edge of metaventrite between coxae; narrow tibiae without outer subapical process; metatarsi particularly narrow and somewhat longer than a half of metatibia. On the other hand, this new genus 
is rather similar to the Neotropical Tagmolycra and Pocadiolycra, but distinct from them in the moderately convex body, explanate pronotal and elytral sides, distinct border along pronotal base at sides of scutellum, more prominent anterior and almost distinct posterior pronotal angles, conspicuous dorsal pubescence; and also from the first Parapocadius gen. nov. differs from in rather convergent antennal grooves and narrow tibiae, including mesotibia and not sharply acute apex of ovipositor; from the second differs in the distinct longitudinal rows on elytra.

Composition. The new genus includes the only species.

Distribution. The range of this new genus is yet restricted by the type locality of its type species.

17. The synonymy Cychramus and Aethinopsis syn. nov. is evident, because the „differences“ used for the proposal of the latter (4-segmented antennal club in males and contrasting coloration of pubescence) are quite characteristic of representatives of Cychramus. A. Grouvelle (1908) erroneously regarded Aethinopsis as close to Aethina and different from the latter in the long antennae.

18. The groups formerly considered as Mystrops and Cryptoraea syn. nov. distinguished mostly presence of the characters of sexual dimorphism in some structures of the members of the first and absence of it in the second (Kirejtshuk \& Jelínek, 2000). Indeed expression of all characters of sexual dimorphism in many species is quite variable and in many cases small males have appearance scarcely different from the females of the same species (Kirejtshuk \& Couturier, in press).

19. The genus Meoncerus (type species: $M e$ oncerus salvini Sharp, 1891, here designated) is quite different from Apsectochilus and Lordyrops, but all these names erroneously synonymyzed by Leschen, 1999. Indeed the Meoncerus is very similar and seems to be closely related to the genus Camptodes (the rank of this taxon would be better estimated as a subgeneric, however this change should be done after a more detailed comparison of members of Camptodes).

The names Apsectochilus and Lordyrops were proposed for quite distinct taxa, because Apsectochilus hydroporoides Reitter, 1874 (type species according to designation by Leschen, 1999), in contrast to the members Meoncerus and Lordyrops (the latter is known after the study of the probable type specimen of its type species: Lordyrops deyrollei Reitter, 1875 deposited in the Museum National d'Histoire Naturelle, Paris), demonstrates the essential differences, consisting in the flat prosternal process with rounded posterior edge, diffuse puncturation of elytra, parallel antennal grooves and submetacoxal line following closely posterior edge of coxal cavity. Besides, the pattern of coloration of Lordyrops, in contrast to Apsectochilus and Meoncerus, is more similar to that in species of Phenolia-complex (Nitidulini sensu str.), but not in representatives of Cyllodini in general. These differences should be treated as quite considerable to regard the Apsectochilus and Lordyrops as separate genera.

20. The synonymy of taxa Cyllodes and Mecyllodes syn. nov. is evident because all characters of the latter can be traced in different species of the first. D. Sharp (1891) having proposed Mecyllodes pointed out that this taxon is close to "Strongylus", but distinct from the latter in the narrowly separate meso- and metacoxae. Besides, the posterior edge of metaventrite of Mecyllodes nigropictus Sharp, 1891 is comparatively deeply excised, while in most species of Cyllodes this edge nearly straight or slightly emarginate. Perhaps, this taxon could be recognized as a subgenus of Cyllodes, however at the moment it is difficult to outline the scope of this subgenus and its hiatus from Cyllodes sensu str.

21. The genus Pallodes is rather diverse and includes many species (mostly still undescribed). They widely spread through all continents, except Antarctica, although the most species occur in the areas with subtropical and tropical climate. Different groups of the genus seem to be characterized by constant structural features and could be regarded as separate taxa, while few related species with very short prosternum are united in the subgenus Coxollodes (stat. nov.) spread in the Eastern Hemisphere. The current taxonomic distribution of the species formerly put in the Pallodes in Grouvelle, 1913 and composition of Neopallodes and Pallodes is given taking into consideration the further descriptions:

Camptodes: C. ruficornis (Grouvelle, 1898), comb. nov. (Pallodes); $C$. grouvellei nom. nov. (pro Pallodes laetus Grouvelle, 1898, non Kirsch, 1873) [This species is distinct according to the here designated lectotype deposited in the Natural History Museum in London ("Amazon, Bates", "Mus. Murray", "Type", "Pallodes laetus Grouv. ty.", written by A. Grouvelle) due to the dull reddish dorsum with slight irridescence on elytra, rather long antennal club, prosternal process rather widened before widely rounded apex, aracteristic shape of tibiae and aedeagus].

Coxollodes: C. cyrtusoides (Reitter, 1884) (?=amamiensis Hisamatsu, 1956), comb. nov. (Pallodes); C. opacus (Grouvelle, 1906), comb. nov. (Pallodes) (= loriai Grouvelle, 1906, syn. nov.); C. parvulus (Grouvelle, 1908), comb. nov. (Pallodes); C. reitteri Kirejtshuk, 1987, comb. nov. (Pallodes);

Cyllodes: C. jucundus (Reitter, 1873), comb. nov. (Pallodes) (=nigropictus Sharp, 1891, syn. nov., Mecyllodes); 
Neopallodes: N. adornans Kirejtshuk, 1987; N. aestimabilis (Grouvelle, 1906), comb. nov. (Pallodes); N. affinis Kirejtshuk, 1994; N. alluaudi (Grouvelle, 1899), comb. nov. (Pallodes); N. aterrimus (Grouvelle, 1906), comb. nov. (Pallodes); N. clavatus (Reitter, 1884) (Pallodes); N. dentatus Grouvelle, 1892; N. diffusus Kirejtshuk, 1994; N. dorsalis (Grouvelle, 1896), comb. nov. (Pallodes); N. ebenus Kirejtshuk, 1994; N. fairmairei (Grouvelle, 1906), comb. nov. (Pallodes); $N$. falsus (Grouvelle, 1912) (Pallodes) (=harmandi Grouvelle, 1903, non Grouvelle, 1902; lindskogi Kirejtshuk, 1987); N. glaesus Kirejtshuk, 1994; N. globosus Kirejtshuk, 1994; N. grouvellei Kirejtshuk, 1987; N. harmandi Grouvelle, 1902; N. hilleri (Reitter, 1877) (Pallodes) (=circumflexus Reitter, 1879); N. incertus (Grouvelle, 1906), comb. nov. (Pallodes); N. inermis Reitter, 1884; N. klugi (Grouvelle, 1896), comb. nov. (Pallodes); $N$. limbicollis (Reitter, 1880), comb. nov. (Pallodes); N. militaris (Grouvelle, 1906), comb. nov. (Pallodes); N. niger (Grouvelle, 1906), comb. nov. (Pallodes); N. nigrocyaneus (Grouvelle, 1906), comb. nov. (Pallodes); N. nitidus (Grouvelle, 1906), comb. nov. (Pallodes); N. omogonis Hisamatsu, 1953; N. orthogonus (Grouvelle, 1906), comb. nov. (Pallodes); N. perrieri (Grouvelle, 1906), comb. nov. (Pallodes); N. scutellaris (Grouvelle, 1906), comb. nov. (Pallodes); N. sicardi (Grouvelle, 1906), comb. nov. (Pallodes); N. sikordi (Grouvelle, 1896), comb. nov. (Pallodes); $N$. simillimus Kirejtshuk, 1994; N. solaris Kirejtshuk, 1987; N. striatopunctatus Kirrejtshuk, 1994; N. subdentatus Kirejtshuk, 1994; N. turulosus Kirejtshuk, 1994; N. variabilis (Grouvelle, 1896), comb. nov. (Pallodes); N. vicinus Grouvelle, 1892; N. vietnamicus Kirejtshuk, 1987;

Pallodes: P. antipodum Grouvelle, 1903; P. alutaceus Kirejtshuk, 1987; P. austrianus Leschen, 1988; P. beccarii Grouvelle, 1906; P. birmanicus Grouvelle, 1892 (=kalingus Kirejtshuk, 1987, syn. nov.); $P$. castaneus Grouvelle, 1914; $P$. cinctus Grouvelle, 1914; P. discoideus Grouvelle, 1898; P. fauveli (Grouvelle, 1903), comb. nov. (Cyllodes) (=vagepunctus Grouvelle, 1903, syn. nov.); P. feai Grouvelle, 1892 (emmend. Feae); $P$. flaccus Kirejtshuk, 1987; P. gestroi Grouvelle, 1906 (=misellus Grouvelle, 1906, syn. nov.); $P$. hiekei Kirejtshuk, 1987; P. kaszabi Kirejtshuk, 1987; P. mexicanus Sharp, 1891; P. oleosus Kirejtshuk, 1987; P. pallidus (Beauvois, 1805) (Sphaeridius) (=silaceus Erichson, 1843; unistriatus Horn, 1885); P. parvus Grouvelle, 1903; $P$. pictus Sharp, 1891; P. plateosus Schaeffer, 1931; P. ruficollis Reitter, 1873 (=cyanescens Grouvelle, 1898, syn. nov.); P. rufidorsis Grouvelle, 1903; P. silaceus Erichson, 1843; Pallodes suffuscus Kirejtshuk, 1987; P. umbratilis Reitter, 1873;
Provisionally Pallodes (not tested by the writer): P. abdominalis Sharp, 1891; P. annulifer (Laporte de Castelneau, 1840) (Strongylus); P. bohemani Grouvelle, 1898; P. bouvieri Grouvelle, 1902; P. brunnipennis Kirsch, 1873; P. cyrcynoides Sharp, 1891; P. deletus Sharp, 1891; P. filipes Sharp, 1891; P. gracilipes Kirsch, 1873; P. guttatus Sharp, 1891; P. marginicollis Reitter, 1875; P. micans Sharp, 1891; P. obscurus Sharp, 1891; $P$. pallidus Reitter, 1875 non Beauvois, 1805; $P$. punctatus Sharp, 1891; $P$. regularis Sharp, 1891; $P$. reversus Sharp, 1891; $P$ scutatus Grouvelle, 1906; P. sellatus Sharp, 1891; P. signaticollis Sharp, 1891; P. sjoestedti Grouvelle, 1909; P. smithi Sharp, 1891; P. strongyliformis Sharp, 1891; P. translatus Grouvelle, 1912 (=smithi Grouvelle, 1898, non Sharp, 1891); P. viridus Sharp, 1891;

Parapocadius gen. nov.: P. immerizi (Grouvelle, 1899), comb. nov. (Pallodes) - see notes 16;

Erotylidae incertae sedis (tested by the writer): "Pallodes cardoni" Grouvelle, 1894.

22. The genus Interfaxia gen. nov. (type species: Psilopyga fasciata Sharp, 1891) [Interfaxia fasciata (Sharp, 1891), comb. nov.]

[the author studied the holotype Psilopyga fasciata (Mexico, "Truqui"), $\sigma$, deposited in the Natural History Museum in London].

Etymology. The name of this new genus is devoted to the agency "Interfax Information Service", where the friends of the author since school-days work, M.V. Komissar, V.A. Polyak and M.L. Andelman.

Remarks. This genus is proposed to counterbalance the related groups of large Cyllodini spread at both side of Pacific and Indian Oceans. A. Grouvelle (1913) united Oxycnemus, Eugoniopus and Psilopyga in one genus without subgeneric separation. Later K. Spornraft (1971) found reasonable to consider to subgenera Oxycnemus and Psilopyga (the species of Eugoniopus were put into the latter). However, these three names can be attributed to the groups which should be regarded as separate genera, while one group described in the composition of Psilopyga ( $P$. fasciata) shares some characters from different groups of Eastern and Western Hemispheres. Besides, this species, in contrast to all mentioned groups and most other Cyllodini, has antennal grooves distinctly divergent, while its submental ridges convergent. Therefore this species would be better to interpret as a form isolated from all mentioned and propose for it a separate genus.

Diagnosis. Four groups here regarded as genera Eugoniopus, Interfaxia gen. nov., Oxycnemus and Psilopyga are closely related and could be discriminated according to the following characters:

Interfaxia gen. nov.:

- widely truncate elytral apices;

- male pygidium with rounded apex; 
- metacoxae about as widely separated as procoxae;

- antennal grooves slightly and rectilinearly convergent;

- submental ridges distinctly raised and convergent;

- distance between mesocoxae about as great as that betweem procoxae and markedly smaller than that between metacoxae;

- posterior edge of metaventrite between coxae nearly straight;

- outer angle of tibiae strongly projecting;

- length of penis trunk markedly smaller that of tegmen;

- distributed in the Western Hemisphere.

Oxycnemus:

- more or less rounded elytral apices;

- male pygidium with rounded apex;

- metacoxae about as widely separated as procoxae;

- antennal grooves subparallel-sided;

- submental ridges not raised;

- distance between mesocoxae more or less greater than that betweem pro- and metacoxae;

- posterior edge of metaventrite between coxae deeply emarginate to angularly excised;

- outer angle of tibiae at most slightly projecting;

- length of penis trunk comparable with that of tegmen;

- distributed in the Western Hemisphere.

Psilopyga:

- widely truncate elytral apices;

- male pygidium with widely truncate apex (from under which the anal sclerite is exposed);

- metacoxae much more widely separated than procoxae;

- antennal grooves distinctly divergent;

- submental ridges not raised;

- distance between mesocoxae greater than that betweem procoxae;

- distance between mesocoxae more or less greater than that betweem procoxae, but distinctly smaller than that between metacoxae;

- posterior edge of metaventrite between coxae nearly straight;

- outer angle of tibiae slightly projecting;

- length of penis trunk markedly smaller than that of tegmen;

- distributed in the Western Hemisphere.

Eugonipus:

- widely truncate elytral apices;

- male pygidium with widely truncate apex (from under which the anal sclerite is exposed);

- metacoxae much more widely separated than procoxae;

- antennal grooves strongly and arcuately convergent;

- submental ridges not raised;
- distance between mesocoxae about as great as or slightly greater than that betweem procoxae, but much smaller than that between metacoxae;

- posterior edge of metaventrite between coxae nearly straight to slightly emarginate;

- outer angle of tibiae not strongly projecting;

- length of penis trunk markedly smaller than that of tegmen;

- distributed in the Eastern Hemisphere.

Interfaxia fasciata comb. nov. somewhat looks like the members of the Eastern Hemispheran Triacanus (Indo-Malayan Region and Palaearchearctic Province), Monafricus (Afrotropical Region) and Gymnocychramus (Australian Region), but differs from all of them in the presence of distinct submental ridges and rather widely separated metacoxae; and also differs from the first in the oval antennal club, not sharply triacuminate apex of prosternal process; from the second in the narrow antennal club, not sharply pointed apex of prosternal process; and from the third in the divergent antennal grooves, not narrow prosternal process, markedly shorter elytra remaining uncovered most part of pygidium, widely truncate apex of male pygidium and anal sclerite well exposed from under it, strongly projecting outer angle of tibiae and rather narrow metatarsi.

Finally, each of the above considered groups of Cyllodini as other Cyllodini in general have the quite characteristic structure of anterior part of metaventrite, which is congruous to the apex of prosternal process, and respectively the peculiar outline of the intercoxal line (if present).

23. The names Grammorus Murray, 1868 and Colopteroides Watrous, 1982, syn. nov. were proposed as monotypic and for the same species named as Grammophorus caelatus Gerstäcker, 1864 and Colopterus striaticollis Murray, 1864, syn. nov. The latter synonymy is based on study of the holotype of G. caelatus, + , deposited in the Museum f. Naturkunde an der Humboldt-Universität, Berlin - "caelatus N., Columb., Mor.", "8330" and holotype of C. striaticollis deposited in Naturhistoriska Riksmuseet, Stockholm - "Rio Jan", "F. Sahlb." There have been studied also 2 우 - "Dr Moritz, 1858, Venezuela", "caelatus Gerst., Columb." and 1 specimen without abdomen - black quadrangle, "720" deposited in the Naturhistorisches Museum, Vienna. The further 3 specimens are in the Canadian Museum of Nature (Ottawa) and Zoological Institute of the Russian Academy of Sciences, St. Petersburg (1 ex. - "C.R., Alajela, Penas Blancas, 9.VII.1987, E. Cruz MT"; 2 exx. - "Ecu.: Pich. Prov., 47 km S Sto. Domingo, Rio Palenco Stn., 18-30.V.1975, S. \& J. Peck").

24. The subgenus Onicotis Murray, 1864 was proposed for one species, strongly different from other members of the genus, therefore it is here 
regarded as a separate genus (stat. nov.). The greatest difference of Onicotis auritus Murray, 1864 , comb. nov. from all groups of the subfamily is concave underside, including slopping externally prohypomera and epipleura. Its scape strongly is exposed externally and the apex of extended process is reaching the anterior angle of pronotum. Its genae outside antennal grooves are strongly projecting anteriorly and reaching the level of outer angle of the mandibles and forming with the latter and external edge of scape a joint continuous curve. These features are also unique among the members of the subfamily. Besides, the tarsi of its legs are rather wide and outline of body (sides and apex of abdomen, sides of pronotum and elytra) with long cilia reminiscent of those in Amphicrossus and some representatives of tribe Nitidulini.

25. The names Cryptarcha and Priatelus syn. nov. are certainly synonyms, because the type species of the latter represent a slender member of Cryptarcha., very similar to C. minima (Sharp, 1886). Thus, the type species of Priatelus should obtain the name Cryptarcha optanda (Broun, 1881), comb. nov. [syntype of Priateles optandus Broun, 1881, 9 , deposited in the the Natural History Museum in London - "1166", "Wellington", "Priatelus optandus"; 1 syntype, 9 in the same collection - "1166", "Silverstream, 8-1-1917"]. T. Broun.

\section{Acknowledgements}

It is impossible to list everybody of colleagues who could be mentioned in connection with different kinds of assistance to the author in his study of the family Nitidulidae during many years. However, the author feels an pleasant obligation to express his thanks to M.V.L. Barclay, R. Booth, M.J.D. Brendell, P.M. Hammond, R. Thompson (Natural History Museum in London), P.Yu. Basilewsky, J. Decelle (Musée Royal d'Afrique Central, Tervuren), N. Berti, A. Descarpentries, T. Deuve, A. Nel (Museum National d'Histoire Naturelle, Paris), M. Brancucci, W. Wittmer (Naturhistorisches Museum, Basel), L. Dieckmann, L. Zerche (Deutsches Entomologisches Institut, Müncheberg), F. Hieke, M. Uhlig (Zoologisches Museum an der HumboldtUniversität, Berlin), M. Jäch, M. Janczyk (Naturihistorisches Museum, Wien), J. Jelínek (Národní Muzeum v Praze), C. Johnson (Museum at Manchester University), Z. Kaszab, O. Merkl (Természettudományj Múzeum, Budapest), J. Krikken (Rijkmuseum van Natuurlijke Historie, Leiden), J.F. Lawrence (Division of Entomology, C.S.I.R.O., Canberra), P. Lindskog, B. Viklund (Naturhistoriska Riksmuseet, Stockholm), E.G. Matthews (South Australian Museum, Adelaide), T. Nakane (Asahigaoka-cho), N.B. Nikitsky (Zoological Museum at Moscow State University), A.F. Newton, M. Thayer (Field Museum of Natural History, Chicago), R. Poggi (Museuo Civico di Storia Naturelle, Genova), W. Schawaller (Staatliches Museum f. Naturkunde, Stuttgart), A. Smetana (Biosystematics Research Institute, Ottawa), K. Spornraft (Munich), W. Weitschaft (Geologo-Paläontologisches Institut u. Museum, Hamburg Universität). The author has got a great constructive influence from A.G. Ponomarenko (Palaeontological Institute of
Russian Academy of Sciences, Moscow), A.V. Gorokhov (Zoological Institute of the Russian Academy of Sciences, St. Petersburg), R.A. Crowson (Glasgow University) and A.M. Easton (London). Besides, many scientific organizations supported this study, in particular the author got two grants from the Russian Foundation of Basic Research (07-04-00540-a and 07-04-92105-China State Foundation of Natural Sciences-a), some grants from the Royal Society, Deutsche Forschungsgemeinschaft, Museum National d'Histore Naturelle in Paris and Smithsonian Institution. The author had also the support during some years from the Program of Presidium of the Russian Academy of Sciences "Origin and Evolution of the Biosphere".

\section{References}

Cline, A.R. \& Carlton, C.E. 2004. Review of Lasiodactylus Perty, with description of three new species (Coleoptera: Nitidulidae: Nitidulinae). The Coleopterists Bull., 58(3): 355-368.

Cline, A.R. 2005. Revision of Pocadius Erichson (Coleoptera: Nitidulidae). A dissertation submitted to the Graduate Faculty of Louisiana State University and Agricultural and Mechanical College in partial fulfillment requirements for the degree of Doctor of Philosophy. http://etd.lsu.edu/docs/available/etd11042005-122348/u, nrestricted/Cline_dis.pdf

Dajoz, R. 1980. Description de Orvoenia borneensis n. gen. n. sp., Coléoptère Colydiidae appurtenant a une tribu nouvele. Revue ent fr. (N.S,), 2(4): 190-192.

Grouvelle, A. 1908. Coléoptères de la region Indienne. Rhizodidae, Trogositidae, Nitidulidae, Colydiidae, Cucujidae. (1ere mémoire). Ann. Soc. Ent. Fr., 77: 315-495, pls.

Grouvelle,A. 1913. Byturidae, Nitidulidae. In: W. Junk (ed.). Coleopterorum Catalogus. Berlin, 15, 56: 1-223.

Hayashi, N. 1978. A contribution to the knowledge of the larvae of Nitidulidae occuring in Japan (Coleoptera: Cucujoidea). Insecta Matsum., N.S., 14: 1-97.

Jelínek, J. 1975. Redescriptions of genera Hebascus Er. And Teichostethus Sharp with designations of their type species (Coleoptera, Nitidulidae). Annatationes Zool. et Bot., 101: 1-12.

Jelínek, J. 1999. Contribution to taxonomy of the beetle subfamily Nitidulinae (Coleoptera: Nitidulidae). Folia Herovskyana, 7(5): 251-281.

Jelínek, J. \& Audisio, P. 2003. Type species fixation and nomenclatural corrections in some taxa of Palaearctic Nitidulidae and Kateretidae (Coleoptera. Folia Heyrovskyana, 11(3-4): 159-171.

Jelínek, J. \& Audisio, P. 2007. Nitidulidae. 459-491. In: Lobl I. \& Smetana A. Catalogue of Palaearctic Coleoptera, Apollo Books, Stenstrup, 4: 935 p.

Kirejtshuk, A.G. 1986. Analysis of structure of genitalia for reconstruction of phylogeny and substantiation of system of the family of sap beetles (Nitidulidae, Coleoptera). Proc. All-Union Ent. Soc., 68: 22-28. (In Russian).

Kirejtshuk, A.G. 1987. New species of the Cyllodes complex of genera (Coleoptera, Nitidulidae) from Indochina and adjacent territoriesa. In: Entomofauna Vietnama [Entomofauna of Vietnam], Moscow, Nauka, 137-170. (In Russian).

Kirejtshuk, A.G. 1996. System, evolution of mode of life and phylogeny of the order Coleoptera. II. Ent. Obozr., 75(1): 39-62. (in Russian) [translation - 1997. System, evolution of mode of life, and phylogeny of the order Coleoptera. II. Ent. review, 76(1): 1-20].

Kirejtshuk, A.G. 1998/1999. Nitidulidae (Coleoptera) of the Himalayas and Northern Indochina. Part 1: 
subfamily Epuraeinae. Koeningstein, Koeltz Scientific Books (Theses Zoologicae, Vol. 28): 1-489.

Kirejtshuk, A.G. 2001. Notes on the systematics of the African Nitidulidae (Coleoptera). Ann. Hist. Nat. Mus. Nation. Hung., 93: 17-89.

Kirejtshuk, A.G. \& Couturier, G. in press. Sap beetles of the tribe Mystropini (Coleoptera, Nitidulidae) associated with inflorescences of the palms cultivated in South America. Ann. Soc. Ent. Fr.

Kirejtshuk, A.G. \& Jelínek, J. 2000. Preliminary review of genera of the tribe Mystropini with redescriptions and new descriptions of some genera, subgenera and species (Coleoptera: Nitidulidae: Nitidulinae). Folia Heyrovskyana, 8(3-4): 171-192.

Kirejtshuk, A.G. \& Lawrence, J.F. 1992. Review of the Thalycrodes-complex of genera (Coleoptera, Nitidulidae), endemic to the Australian region. J. Austral. Ent. Soc., 31: 119-142.

Kirejtshuk, A.G. \& Lawrence, J.F. 1999. Notes on the Aethina complex (Coleoptera: Nitidulidae: Nitidulinae) with a review of the Aethina (Cleidorura) subgen.n. and Aethina (Idaethina) Gemminger \& Harold. Ann Zool., 49(3): 233-254.

Kirejtshuk, A.G. \& Ponomarenko, A.G. 1990. Fossil beetles of the families Peltidae and Nitidulidae. Paleontolog. Zhurnal, 2: 78-88+1 pl.

Leschen, R.A.B., 1999. Systematics of Nitidulinae (Coleoptera: Nitidulidae): phylogenetic relationships, convexity and the origin of phallophagy. Invertebrate Taxonomy, 13: 845-882.
Motschulsky, V. 1858. Etudes Entomologiques. Helsingfors, 7: 192 pp. + Taf. 2.

Murray, A. 1864. Monograph of the family Nitidulidulariae. Trans. Linn. Soc. London, 24: 212-414, pls. 32-36.

Pal, T.K. and Lawrence, J.F. 1986. A new genus and subfamily of the mycophagous Bothrideridae (Coleoptera: Cucujoidea) from the Indo-Australian region, with notes on related families. Journal of Australian Entomological Society, 25(3): 185-210.

Parsons, C.T. 1943. A revision of Nearctic Nitidulidae (Coleoptera). Bull. Mus. Compar. Zoöl., 92(3): 121$278+13$ pls

Perkovsky, E.E. 1990. First discovering of Cretaceous insects of the family Leiodidae (Coleoptera) Paleontolog. Zhurnal, 4: 118-120. (In Russian).

Ponomarenko,A.G. \& Kirejtshuk, A.G. 2008. Taxonomic list of fossil beetles of suborder Scarabaeina (Part 3) http://www.zin.ru/Animalia/Coleoptera/eng/paleosys2. htm (April 2008).

Sharp, D. 1891. Fam. Nitidulidae. 265-388, 8-12 tabs. In: Sharp D., Matthews A. \& Lewis G. 1887-1905. Biologia Centrali-Americana. Insecta. Coleoptera, 2(1): 717 p., 19 tabs.

Spornraft, K. 1971. Zwei neue Arten der Gattung Oxycnemus Er. Und Bestimmungtabelle für die bisher bekannten Arten (Coleoptera, Nitidulidae). Opucula Zool., 116: 1-10.

Received 3 April 2008, accepted 10 June 2008. 